\title{
The examination of Yo-Yo intermittent recovery test performance of young soccer players at different playing positions
}

\author{
Serdar Bayrakdaroğlu ${ }^{1 \mathrm{ABCDE}}$, Erdal Ar1 ${ }^{2 \mathrm{ABCDE}}$, Hüseyin Özkamç1 $1^{3 \mathrm{ABCDE}}$, İbrahim Can ${ }^{4 \mathrm{ABCDE}}$ \\ ${ }^{1}$ Gumushane University, Turkey \\ ${ }^{2}$ Ordu University, Turkey \\ ${ }^{3}$ Dokuz Eylul University, Turkey \\ ${ }^{4}$ Igdir University, Turkey
}

Authors' Contribution: A - Study design; B - Data collection; C - Statistical analysis; D - Manuscript Preparation; E - Funds Collection.

\begin{abstract}
Purpose: $\quad$ The aerobic fitness in soccer is an important performance component. The aerobic endurance level of players may positively effect performance of critical match activities. The examination of Yo-Yo intermittent recovery test (YYIRT) performance of young soccer players at different playing positions was aimed in this study.

Material: $\quad$ The research group was consisted of 75 young soccer players playing at U-21 category of professional soccer teams at different leagues. The soccer players at 5 different playing positions participated in study voluntarily (centerback: $n=15$, fullback: midfielder: $n=15$, winger: $n=15$, forward: $n=15$ ). The YYIRT (level 1) was performed for determination aerobic endurance parameters (covered distance during test, maximum oxygen uptake $\left(\mathrm{VO}_{2 \max }\right)$ and maximal aerobic speed (MAS) of players. The one-way ANOVA analysis was used for comparison between playing positions of YYIRT parameters.

Results: It was determined that difference between YYIRT parameters of players at different playing positions was non-significant $(p>0.05)$. However, the midfielders covered more distance $(2425,33 \pm 440,42 \mathrm{~m})$ than forward $(2146,67 \pm 339,64 \mathrm{~m})$, winger $(2137,33 \pm 615,18 \mathrm{~m})$, fullback $(2056,00 \pm 512,43 \mathrm{~m})$ and centerback $(1960,00 \pm 313,51 \mathrm{~m})$ players. The positional requirements of midfielders may be decisive on covered distance during YYIRT.

Conclusions: Consequently, it may be said that the young soccer players at different playing positions had similar YYIRT performance and the playing position effect on YYIRT performance could vary depending on league level and individual features of players.

Keywords: covered distance, aerobic, endurance, soccer, Yo-Yo test.
\end{abstract}

\section{Introduction}

The endurance is one of the most important motoric characteristics at soccer game. The duration of soccer match is 90 minutes and the soccer players perform repeatedly various activities such as sprint, jump, standing, running with turning, intermittent running. The high level endurance assists to players during repeated performance of these activities at soccer match. The requirements of game are decisive on technical and physical activities performed at match. It was indicated that length and intensity of high and low intensity activities during soccer game vary according to various factors [1].The performance of intermittent and repeated activities during soccer game depends on aerobic endurance and recovery capacities of players. The repeated sprints and high intensity running are frequently performed at soccer match. Therefore, aerobic endurance level and recovery capacity of players may affect performance of intermittent and repeated activity during soccer match. It was indicated that the total $10-13 \mathrm{~km}$ distance was covered by elite soccer players at soccer match and the most of this distance was consisted of low intensity activities [2]. However, it was found that the 2-4 seconds sprint running was performed at every 90-180 seconds (c) Serdar Bayrakdaroğlu, Erdal Arı, Hüseyin Özkamçı, İbrahim Can, 2020

doi:10.15561/20755279.2020.0406 of soccer match [3]. There is a dominance of aerobic endurance at soccer match. Also, the intermittent and repeated sprint running are performed throughout soccer match and these anaerobic activities may be decisive on match performance than aerobic activities.

The intermittent and repeated high intensity activities of soccer match is indicator of recovery capacities of players. However, the high level aerobic endurance is basis of recovery capacity at intermittent and repeated activities. The intermittent activity and recovery capacity performance of players is measured by various fitness tests. The Yo-Yo intermittent recovery test (YYIRT) is used for determination of aerobic endurance and recovery capacity. The YYIRT is used commonly at soccer [4]. The YYIRT is a practical, simple, inexpensive and useful test because of testing of a lot of players at single session [5]. The YYIRT includes running with turning and recovery intervals between running. It is known that the running with turning, sprint and short distance activities are available at soccer game. The soccer is a sport branch including intermittent activities and the high intensity activities are splitted with active recovery periods [6]. Therefore, YYIRT may be indicated as soccer specific test protocol including intermittent running [7]. Krustrup et al. [8] found that the distance covered with high intensity running during soccer game was correlated with YYIRT 
performance. Also, it was found that the post-test covered distance values of elite soccer referees increased after intermittent training period [9]. The aerobic endurance level may be followed with YYIRT test performance. The aerobic fitness level of soccer players may be measured before and after training intervention. The increase of aerobic performance may be determined after training period. There are many factors affecting aerobic endurance capacity of young soccer players such as playing position. The physical and physiological requirements of playing position at soccer may differentiate. It is expected that the soccer players increase match performance according to this discrepancy between playing positions. The performance development is important for professional soccer careers of young players. The performance of young soccer players should periodically be tracked and the essential exercises for performance development should be performed in the light of tests.

Although many studies are available about YYIRT performance, there are few studies on young soccer players in the literature. The determination of playing position effect on YYIRT performance of young soccer players may provide useful information for scientific literature. Therefore, the examination of YYIRT performance of young soccer players at different playing positions was aimed in this study.

\section{Material and Methods}

\section{Participants}

The research group was consisted of 75 young soccer players playing at U-21 category of professional soccer teams at different leagues. The soccer players at 5 different playing positions participated in study voluntarily $(n=15$ - centerbacks, $n=15$ - fullbacks, $n=15$ - midfielders, $n=15$ - wingers, $n=15$ - forwards). The descriptive data of age, body height, weight values of young soccer players was indicated in Table 1. The study was performed in line with principles of Helsinki Declaration.

Research Design

Data Collection

Body Height and Weight Measurements

The body height was measured by a stadiometer (Holtain, Holtain Ltd., Dyfed, UK) with $0.1 \mathrm{~cm}$ precision. The body height was measured as length between top point of head and feet at position of standing with bare feet. The body weight was measured by electronic body weight measurement device (Tanita 401A, Tokyo, Japan) with $0.1 \mathrm{~kg}$ precision at bare feet position with sports clothes.
Yo-Yo Intermittent Recovery Level 1 Test

The aerobic fitness level of soccer players was determined by Yo-Yo intermittent recovery level 1 (YYIRT1) test. The test was explained to young soccer players. The warm-up exercises were performed before test. After stretching exercises, the test was performed. The tests of all players were performed at same hour of day to prevent circadian rhythm effects. The YYIRT1 was performed on a $25 \mathrm{~m}$ test track. The test was consisted of $2 \times 20 \mathrm{~m}$ running with turning and $2 \times 5 \mathrm{~m}$ jogging running with 10 seconds for active recovery [8] (Figure 1). After every $40 \mathrm{~m}(2 \times 20 \mathrm{~m})$ running bout, the $2 \times 5 \mathrm{~m}$ jogging running with 10 seconds was performed for active recovery. The starting running speed of test protocol was $10 \mathrm{~km} / \mathrm{h}$. The $4 \times 40 \mathrm{~m}$ running with turning at $10-13 \mathrm{~km} / \mathrm{h}$ speed at $0-160 \mathrm{~m}$ interval (a $40 \mathrm{~m}(2 \times 20 \mathrm{~m})$ at $10,11,12$, $13 \mathrm{~km} / \mathrm{h}$ speed) and $7 \times 40 \mathrm{~m}$ running with turning at 13.5 $14 \mathrm{~km} / \mathrm{h}$ speed at $160-440 \mathrm{~m}$ interval $(3 \times 40 \mathrm{~m}$ at $13.5 \mathrm{~km} / \mathrm{h}$ speed and $4 \times 40 \mathrm{~m}$ at $14 \mathrm{~km} / \mathrm{h}$ speed) were performed. Then, the increase of running speed was $0.5 \mathrm{~km} / \mathrm{h}$ at every $320 \mathrm{~m}$ (at every bout of $8 \times 40 \mathrm{~m}$ running with turning). The running speed was announced with audio signals emitted by a transportable CD player (Philips Az1030, Eindhoven, Holland). The players arrived $20 \mathrm{~m}$ cones of test track at every audio signal. The test was ended when the audio signal was not caught by players at $20 \mathrm{~m}$ cones or players left test willingly (exhaustion). The covered distance was recorded as test score. After test, the soccer players performed warm down and stretching exercises for active recovery. The indirect maximal oxygen uptake value was determined in $\mathrm{ml} / \mathrm{kg} / \mathrm{min}$ unit by formula of Bangsbo et al. [10]:

\section{$\mathrm{VO}_{2 \max }(\mathrm{ml} / \mathrm{kg} / \mathrm{min})=$ YYIRT1 distance $(\mathrm{m}) \times 0.0084+36.4$}

The maximal aerobic speed parameter of players was calculated with covered distance value of test according to regression model of Heaney et al. [11]:

Maximal aerobic speed $(\mathrm{m} / \mathrm{sec})=0.456250 \times($ covered distance at YYIRT1 $[\mathrm{km}])+3.617444$

Statistical Analysis

The data of study was presented as descriptive statistics ( $\mathrm{X} \pm \mathrm{SD}$, Min-Max). The Shapiro Wilk test was used for determination the normality of data distribution. The test parameters were compared between playing positions by one way analysis of variance (one way ANOVA). The Levene's Test was used for determination the homogeneity of variance. The pairwise comparisons of significant difference determined between playing position groups were determined by Games-Howell test. The significance level of statistical analysis was

Table 1. The descriptive statistics of age, body weight and height of young soccer players

\begin{tabular}{llllllllllll}
\hline \multirow{2}{*}{ Parameter } & \multicolumn{2}{l}{ Centerback } & \multicolumn{2}{c}{ Fullback } & \multicolumn{2}{c}{ Midfielder } & Winger & \multicolumn{3}{c}{ Forward } \\
\cline { 2 - 12 } & $\overline{\mathbf{X}}$ & SD & $\overline{\mathbf{X}}$ & SD & $\overline{\mathbf{X}}$ & SD & $\overline{\mathbf{X}}$ & SD & $\overline{\mathbf{X}}$ & SD \\
\hline Age (years) & 20.33 & 0.48 & 20.26 & 0.45 & 20.04 & 0,50 & 20,02 & 0,41 & 20,01 & 0,35 \\
Body weight (kg) & 76.47 & 6.32 & 74.35 & 5.45 & 75.20 & 4,12 & 72,70 & 2,60 & 78,40 & 6,80 \\
Body height (cm) & 180.00 & 7.60 & 175.00 & 5.20 & 178.00 & 5,40 & 174,00 & 4,40 & 181,00 & 3,50 \\
\hline
\end{tabular}


performed as $\mathrm{p}<0.05$.

\section{Results}

In Table1, it was seen that the midfielders had the highest Max. $\mathrm{VO}_{2}$, distance and MAS values than other playing positions. However, it was determined that the test values of the centerback players was the lowest of all playing positions.
According to analysis results, no significant difference was determined between young soccer players at different playing positions in terms of the $\mathrm{VO}_{2 \max }$, covered distance and MAS values. The analysis results indicated that the midfielders had the highest test values than soccer players at other playing position, but this difference was not statistically significant.

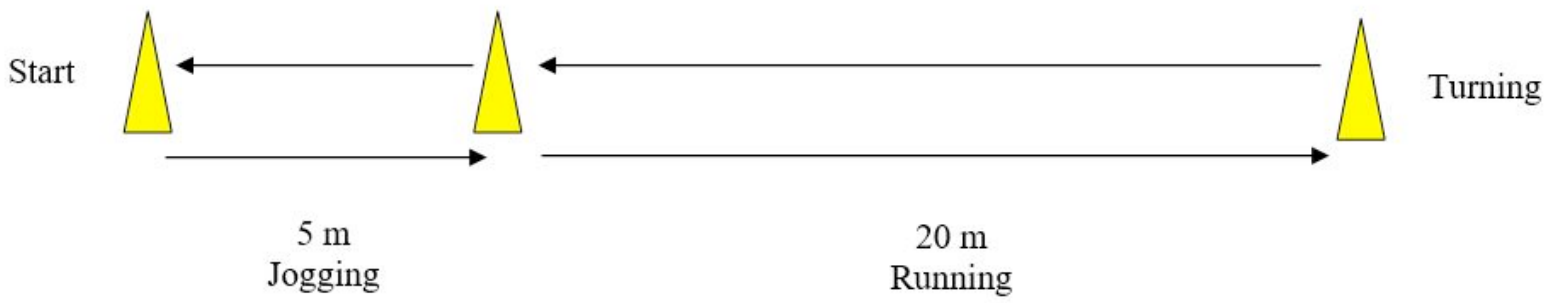

Figure 1. Yo-Yo Intermittent Recovery Level 1 Test Track

Table 2. YYIRT1 values of young soccer players at different playing positions

\begin{tabular}{|c|c|c|c|c|}
\hline Playing Position & Parameter & $\overline{\mathbf{x}}$ & SD & Min.-Max. \\
\hline Centerback $(n=15)$ & $\begin{array}{l}\mathrm{VO}_{2 \max }(\mathrm{ml} / \mathrm{kg} / \mathrm{dk}) \\
\text { Distance }(\mathrm{m}) \\
\mathrm{MAS}(\mathrm{m} / \mathrm{sec})\end{array}$ & $\begin{array}{l}52.86 \\
1960.00 \\
4.51 \\
\end{array}$ & $\begin{array}{l}2.63 \\
313.51 \\
0.14\end{array}$ & $\begin{array}{l}47.15-57.57 \\
1280.00-2520.00 \\
4.20-4.77\end{array}$ \\
\hline $\begin{array}{l}\text { Fullback } \\
(n=15)\end{array}$ & $\begin{array}{l}\mathrm{VO}_{2 \max }(\mathrm{ml} / \mathrm{kg} / \mathrm{dk}) \\
\text { Distance }(\mathrm{m}) \\
\mathrm{MAS}(\mathrm{m} / \mathrm{sec})\end{array}$ & $\begin{array}{l}53.67 \\
2056.00 \\
4.55\end{array}$ & $\begin{array}{l}4.30 \\
512.43 \\
0.23\end{array}$ & $\begin{array}{l}48.83-63.95 \\
1480.00-3280.00 \\
4.29-5.11\end{array}$ \\
\hline $\begin{array}{l}\text { Midfielder } \\
(n=15)\end{array}$ & $\begin{array}{l}\mathrm{VO}_{2 \max }(\mathrm{ml} / \mathrm{kg} / \mathrm{dk}) \\
\text { Distance }(\mathrm{m}) \\
\mathrm{MAS}(\mathrm{m} / \mathrm{sec})\end{array}$ & $\begin{array}{l}56.77 \\
2425.33 \\
4.72\end{array}$ & $\begin{array}{l}3.70 \\
440.42 \\
0.20\end{array}$ & $\begin{array}{l}52.53-62.27 \\
1920.00-3080.00 \\
4.49-5.02\end{array}$ \\
\hline $\begin{array}{l}\text { Winger } \\
(n=15)\end{array}$ & $\begin{array}{l}\mathrm{VO}_{2 \max }(\mathrm{ml} / \mathrm{kg} / \mathrm{dk}) \\
\text { Distance }(\mathrm{m}) \\
\mathrm{MAS}(\mathrm{m} / \mathrm{sec})\end{array}$ & $\begin{array}{l}54.35 \\
2137.33 \\
4.59\end{array}$ & $\begin{array}{l}5.17 \\
615.18 \\
0.28\end{array}$ & $\begin{array}{l}45.81-64.29 \\
1120.00-3320.00 \\
4.13-5.13\end{array}$ \\
\hline $\begin{array}{l}\text { Forward } \\
(n=15)\end{array}$ & $\begin{array}{l}\mathrm{VO}_{2 \max }(\mathrm{ml} / \mathrm{kg} / \mathrm{dk}) \\
\text { Distance }(\mathrm{m}) \\
\mathrm{MAS}(\mathrm{m} / \mathrm{sec})\end{array}$ & $\begin{array}{l}54.43 \\
2146.67 \\
4.60\end{array}$ & $\begin{array}{l}2.85 \\
339.64 \\
0.16\end{array}$ & $\begin{array}{l}47.82-59.58 \\
1360.00-2760.00 \\
4.24-4.88\end{array}$ \\
\hline $\begin{array}{l}\text { Total } \\
(n=75)\end{array}$ & $\begin{array}{l}\mathrm{VO}_{2 \max }(\mathrm{ml} / \mathrm{kg} / \mathrm{dk}) \\
\text { Distance }(\mathrm{m}) \\
\mathrm{MAS}(\mathrm{m} / \mathrm{sec})\end{array}$ & $\begin{array}{l}54.42 \\
2145.07 \\
4.60\end{array}$ & $\begin{array}{l}3.97 \\
472.10 \\
0.21\end{array}$ & $\begin{array}{l}45.81-64.29 \\
1120.00-3320.00 \\
4.13-5.13\end{array}$ \\
\hline
\end{tabular}

Note:MAS - maximal aerobic speed

Table 3. The one-way anova results of $\mathrm{VO}_{2 \text { max }}$ covered distance and maximal aerobic speed values duringyyırt1 of young soccer players at different playing positions

\begin{tabular}{|c|c|c|c|c|c|c|}
\hline Parameter & Playing Position & $\mathbf{n}$ & $\overline{\mathbf{X}}$ & SD & $\mathbf{F}$ & $p$ \\
\hline \multirow{5}{*}{$\mathrm{VO}_{2 \max }$} & Centerback & 15 & 52.86 & 2.63 & \multirow{5}{*}{2.158} & \multirow{5}{*}{0,083} \\
\hline & Fullback & 15 & 53.67 & 4.30 & & \\
\hline & Midfielder & 15 & 56.77 & 3.70 & & \\
\hline & Winger & 15 & 54.35 & 5.17 & & \\
\hline & Forward & 15 & 54.43 & 2.85 & & \\
\hline \multirow{5}{*}{ Covered Distance } & Centerback & 15 & 1960.00 & 313.51 & \multirow{5}{*}{2.160} & \multirow{5}{*}{0,082} \\
\hline & Fullback & 15 & 2056.00 & 512.43 & & \\
\hline & Midfielder & 15 & 2425.33 & 440.42 & & \\
\hline & Winger & 15 & 2137.33 & 615.18 & & \\
\hline & Forward & 15 & 2146.67 & 339.64 & & \\
\hline \multirow{5}{*}{ MAS } & Centerback & 15 & 4.51 & 0.14 & \multirow{5}{*}{2.133} & \multirow{5}{*}{0,086} \\
\hline & Fullback & 15 & 4.55 & 0.23 & & \\
\hline & Midfielder & 15 & 4.72 & 0.20 & & \\
\hline & Winger & 15 & 4.59 & 0.28 & & \\
\hline & Forward & 15 & 4.60 & 0.16 & & \\
\hline
\end{tabular}

Note:MAS - maximal aerobic speed 


\section{Discussion}

It was determined that difference between YYIRT1 performance of soccer players at different playing positions was statistically non-significant. The young soccer players playing at under 21 age categories joined to this study. These soccer players were candidates to professionalism in their teams. The YYIRT1 performance of midfielders was higher than other soccer players at other playing positions but this difference was not statistically significant. This difference may cause from workload of midfielder players. Cihan et al.[12] reported that professional midfielders had more covered distance and higher $\mathrm{VO}_{2 \max }$ values at YYIRT1 test than defence, forward players and goalkeepers. Although there was no significant difference between test values of young soccer players at different playing positions, there was a similarity between results of two study in terms of better test values of midfielders. The professional soccer players may have higher test values and the results of mentioned study may arise from this factor. Similarly, Mohr et al. [13] found that midfielders and fullback players covered more distance than forward and defence players duringYYIRT1. The midfielders have important role on game tactic and structure of team. Therefore, the performance of midfielders is decisive of performance at soccer match. It was determined that covered distance and $\mathrm{VO}_{2 \max }$ values at Yo-Yo intermittent recovery level 2 (YYIRT2) test of defence and midfield players were higher than forward players and goalkeepers at study performed on young soccer players of Slovakia U-21 (under 21 age) national team [14]. Although the loading intensity of the YYIRT2 test was higher than YYIRT1, it was seen that the covered distance and $\mathrm{VO}_{2 \max }$ values of midfielders during test was higher than other playing positions similarly to findings of our study. Markovic and Mikulic [15] determined that the covered distance values during YYIRT1 of young midfielders and wingers was higher than other playing positions but this difference was not statistically significant. Similarly, Mohr and Krustrup [16] reported that semi-professional male wingers covered significantly more distance during YYIRT1 than fullback and attacker players. Also, the covered distance during test of central midfielders was higher than centerback, fullback and attacker players in mentioned study. In study performed on male soccer players aged 23 years, it was found that midfielders covered more distance than defenders and less distance than attacker players [17]. It was remarkable that the findings of our study were similar to findings of mentioned studies.

Rago et al. [18] indicated that defenders covered more distance than midfielder and attacker players in sub-elite soccer players at under 19 age. The defender players were divided to two categories as centerback and fullback in our study such as most studies. The YYIRT1 values of centerback and fullback was the lowest of all playing positions. The game tactics and strategies may vary between soccer teams. The defensive and offensive game strategies are performed during soccer matches at different forms and levels according to various factors (such as features of own and opponent's players, match status, pitch condition). Therefore, the discrepancy between our study and mentioned study may arise from these factors. On the other hand, the significant difference between covered distance values duringYYIRT1 of goalkeepers, defenders, midfielders and attackers was not determined [19]. Although the physical and conditional features of male and female soccer players is different, the results of our study draw parallelism to findings of mentioned study. The values of covered distance during YYIRT1 in our study was higher than test values of Milanović et al [19] but no significant difference was determined between playing positions at both two studies. The physical and conditional features of soccer players at different playing positions may be similar. The parallelism between two studies may arise from this similarity.

The YYIRT1 performance is correlated with soccer match performance. This relationship was emphasized by many studies. Dupont et al. [20] found a correlation between YYIRT1 peak velocity and maximal aerobic velocity of Montreal Track test $(\mathrm{r}=0.79, \mathrm{p}<0.01)$. Also, Krustrup et al. [8] determined that the YYIRT1 performance was significantly correlated with the covered distance with high intensity running during soccer match $(r=0.71, p<0.05)$. Similarly, it was found that the covered distance during YYIRT1 was significantly correlated with soccer match performance (covered distance with high intensity activity $(\mathrm{r}=0.77)$ and total covered distance $(\mathrm{r}=0.65)$ during soccer match) [21]. In another study, Castagna et al. [22] determined moderate and high correlations between covered distance during YYIRT1 and soccer match activities with high intensity (covered distance with high intensity activity $(\mathrm{r}=0.73)$, covered distance with high intensity running $(\mathrm{r}=0.65)$ and sprint distance $(\mathrm{r}=0.76))$. The $\mathrm{VO}_{2 \max }$ value is an important indicator of aerobic endurance. It was indicated that the YYIRT1 performance is strongly related to $\mathrm{VO}_{2 \max }$ value in many studies. Aslan et al. [23] reported high correlation between covered distance during YYIRT1 and $\mathrm{VO}_{2 \max }$ values $(\mathrm{r}=0.89)$. Wong et al. [24] performed a study on U-14 (under 14 age) and found a correlation between covered distance during YYIRT1 and Hoff dribbling test (specific soccer test) performance and $\mathrm{VO}_{2 \max }$ value $(\mathrm{r}=0,71$ and $\mathrm{r}=0.63$, respectively). Rampinini et al. [25] determined that YYIRT1 distance value was correlated with Max. $\mathrm{VO}_{2}$ value. Similarly, it was found that YYIRT2 test performance is related to covered distance during soccer match. Alonso et al. [26] performed a study on young soccer players and found a correlation between covered distance during YYIRT2 test and covered distance with middle intensity and high intensity and total covered distance $(\mathrm{r}=0.456, \mathrm{r}=0.451, \mathrm{r}=0.581$, respectively). In young soccer players aged 14-17, the covered distance during YYIRT1 was correlated with covered distance with high intensity running $(\mathrm{r}=0.56)$, high intensity activity $(\mathrm{r}=0.56)$, sprint distance $(\mathrm{r}=0.63)$ and sprint time percentage at last 13.3 minutes $(\mathrm{r}=0.63)$ during soccer match [27]. The running with turning, changes of direction, short distance sprints, jumps and 
acceleration are performed during soccer matches. The YYIRT1 includes these activities. Therefore, the test may indicate soccer performance such as findings of mentioned studies.

It is known that the YYIRT1 is a soccer specific test including physical activities used frequently at soccer matches. The YYIRT1 may discriminate aerobic fitness of soccer players. The levels of aerobic endurance and physical condition may be determined by YYIRT1. The many studies examined aerobic fitness level and indicated difference between soccer players at different aerobic fitness level. Veale et al. [28] performed YYIRT1 on soccer players and determined that elite junior soccer players covered more distance than sub-elite and nonathletic general healthy soccer players. Similarly, Deprez et al. [29] found that the covered distance values during YYIRT1 of elite young soccer players were higher than test values of sub-elite young players in study performed on young players at U-13, U-15 and U-17 (under 13, 15 and 17 age) categories. Also, it was determined that the YYIRT1 distance of professional soccer players was higher than test distance of amateur soccer players [25]. In another study performed on young soccer players and active sedentary individuals, the YYIRT1 distance of soccer players at 12-13 age category was higher than test distance of sedentary individuals [30]. In study of Teplan et al. [31], it was found that the YYIRT1 distance was higher at soccer players at U-17 category (under 17 age) than players at U-16 category (under 16 age). The age and maturation effect on physical fitness may decisive on YYIRT1 performance of young soccer players at mentioned study. The results of mentioned studies show that the YYIRT1 performance is an indicator of match performance. The aerobic fitness level of soccer players may be distinctively determined by YYIRT1.

There are different findings in literature about examination ofYYIRT1 performance according to playing position. In our study, it was determined that the difference of YYIRT1 performances between playing positions was statistically non-significant. However, the midfielders had higher YYIRT1 performance than players at other playing positions. The inconsistency of YYIRT1 performance findings in literature may be arisen from aerobic fitness level and individual features of subjects at studies.

\section{Conclusion}

Consequently, it was seen that the young soccer players at different playing positions at U-21 (under 21 age) category had similar YYIRT performance. However, young midfield players may cover more distance in YYIRT1 because of requirements of playing position. It may be performed more studies including young soccer players at different league levels for more comprehensive findings about YYIRT1 performance.

\section{Acknowledgements}

This study was written by abridging Serdar Bayrakdaroğlu, Erdal Arı, Hüseyin Özkamçı and İbrahimCan. No grants or financial aids were taken in this Project.

\section{Financial support}

There is no financial support.

\section{Conflict of interest}

The authors declare no conflict of interest.

6. Deprez D, Fransen J, Lenoir M, Philippaerts RM, Vaeyens R. The Yo-Yo intermittent recovery test level 1 is reliable in young high-level soccer players. Biology of Sport, 2015; 32(1): 65. https://doi.org/10.5604/20831862.1127284

7. Castagna C, Impellizzeri FM, Belardinelli R, Abt G, Coutts A, Chamari K, D'Ottavio S. Cardiorespiratory responses to Yo-yo Intermittent Endurance Test in nonelite youth soccer players. The Journal of Strength and Conditioning Research, 2006; 20(2): 326-330. https://doi.org/10.1519/00124278-200605000-00016

8. Krustrup P, Mohr M, Amstrup T, Rysgaard T, Johansen J, Steensberg A, et al. The Yo-Yo Intermittent Recovery Test: Physiological Response, Reliability, and Validity. Medicine \& Science in Sports \& Exercise, 2003;35:697-705. https://doi.org/10.1249/01.MSS.0000058441.94520.32

9. Krustrup P, Bangsbo J. Physiological demands of topclass soccer refereeing in relation to physical capacity: Effect of intense intermittent exercise training. Journal of Sports Sciences, 2001; 19(11): 881-891. https://doi.org/10.1080/026404101753113831

10.Bangsbo J, Iaia FM, Krustrup P. The Yo-Yo intermittent recovery test. Sports Medicine. 2008; 38(1): 37-51. https://doi.org/10.2165/00007256-200838010-00004

11.Heaney N, Williams M, Lorenzen C, Kemp J. (2009). Comparison of a YOYO IR1 test and a VO2max test as a determination of training speeds and evaluation of 
aerobic power. In: Australian Strength and Conditioning Association International Conference on Applied Strength and Conditioning; Gold Coast: Australia; 2009. P. 100-107.

12.Cihan H, Can İ, Seyis M. Comparison of recovering times and aerobic capacity according to playing positions of elite football players. Journal of Physical Education and Sports Science, 2012; 6(1): 1-8.

13.Mohr M, Krustrup P, Bangsbo J. Match performance of highstandard soccer players with special reference to development of fatigue. Journal of Sports Sciences, 2003; 21(7): 519-528. https://doi.org/10.1080/0264041031000071182

14.Pivovarniček P, Pupiš M, Tonhauserová Z, Tokárová M. Level of sprint and jump abilities and intermittent endurance of elite young soccer players at different positions. SportLogia, 2013; 9(2): 109-117. https://doi.org/10.5550/sgia.130902.en.006P

15.Markovic G, Mikulic P. Discriminative ability of the Yo-Yo intermittent recovery test (level 1) in prospective young soccer players. Journal of Strength and Conditioning Research, 2011; 25(10): 2931-2934. https://doi.org/10.1519/JSC.0b013e318207ed8c

16.Mohr M, Krustrup P. Yo-Yo intermittent recovery test performances within an entire football league during a full season. Journal of Sports Sciences, 2014; 32(4): 315-327. https://doi.org/10.1080/02640414.2013.824598

17.Sparks M, Coetzee B, Gabbett JT. Yo-Yo Intermittent Recovery Test thresholds to determine positional internal match loads of semiprofessional soccer players. International Journal of Performance Analysis in Sport, 2016; 16(3): 1065-1075. https://doi.org/10.1080/24748668.2016.11868948

18.Rago V, Pizzuto F, Raiola G. Relationship between intermittent endurance capacity and match performance according to the playing position in sub-19 professional male football players: Preliminary results. Journal of Physical Education and Sport, 2017; 17(2): 688.

19.Milanović Z, Sporiš G, Trajković N. Differences in body composite and physical match performance in female soccer players according to team position. Journal of Human Sport and Exercise, 2012; 7(1): 67-72. https://doi.org/10.4100/jhse.2012.7.Proc1.08

20.Dupont G, Defontaine M, Bosquet L, Blondel N, Moalla W, Berthoin S. Yo-Yo intermittent recovery test versus the Universite de Montreal Track Test: relation with a high-intensity intermittent exercise. Journal of Science and Medicine in Sport, 2010; 13(1): 146-150. https://doi.org/10.1016/j.jsams.2008.10.007

21.Castagna C, Impellizzeri F, Cecchini E, Rampinini E, Alvarez JCB. Effects of intermittent-endurance fitness on match performance in young male soccer players. The Journal of Strength and Conditioning Research, 2009; 23(7): 1954-1959. https://doi.org/10.1519/JSC.0b013e3181b7f743
22.Castagna C, Manzi V, Impellizzeri F, Weston M, Alvarez JCB. Relationship between endurance field tests and match performance in young soccer players. The Journal of Strength and Conditioning Research, 2010; 24(12): 3227-3233. https://doi.org/10.1519/JSC.0b013e3181e72709

23.Aslan E, Müniroğlu S, Alemdaroğlu UB, Karakoç B. Investigation of the performance responses of yo-yo and shuttle run tests with the treadmill run test in young soccer players. Pamukkale Journal of Sport Sciences, 2012; 3(3): 104-112.

24.Wong PL, Chaouachi A, Castagna C, Lau PW, Chamari $\mathrm{K}$, Wisløff U. Validity of the Yo-Yo intermittent endurance test in young soccer players. European Journal of Sport Science, 2011; 11(5): 309-315. https://doi.org/10.1080/17461391.2010.521579

25.Rampinini E, Sassi A, Azzalin A, Castagna C, Menaspa P, Carlomagno D, Impellizzeri FM. Physiological determinants of Yo-Yo intermittent recovery tests in male soccer players. European Journal of Applied Physiology,2 010; 108(2): 401-409. https://doi.org/10.1007/s00421-009-1221-4

26.Alonso L, Silva L, Paulucio D, Pompeu F, Bezerra L, Lima V, Vale R, Oliveira M, Dantas P, Silva J, Nunes R. Field tests vs. post-game GPS data in young soccer player team. Journal of Exercise Physiology Online, 2017; 20(1).

27.Rebelo A, Brito J, Seabra A, Oliveira J, Krustrup P. Physical match performance of youth football players in relation to physical capacity. European Journal of Sport Science, 2014; 14(sup1): 148-156. https://doi.org/10.1080/17461391.2012.664171

28. Veale JP, Pearce AJ, Carlson JS. The Yo-Yo intermittent recovery test (level 1) to discriminate elite junior Australian football players. Journal of Science and Medicine in Sport, 2010; 13(3): 329-331. https://doi.org/10.1016/j.jsams.2009.03.006

29.Deprez D, Coutts AJ, Lenoir M, Fransen J, Pion J, Philippaerts R, Vaeyens R. Reliability and validity of the Yo-Yo intermittent recovery test level 1 in young soccer players. Journal of Sports Sciences, 2014; 32(10): 903-910. https://doi.org/10.1080/02640414.2013.876088

30.Póvoas SC, Castagna C, Soares JM, Silva PM, Lopes MV, Krustrup P. Reliability and validity of Yo-Yo tests in 9-to 16-year-old football players and matched non-sports active schoolboys. European Journal of Sport Science, 2016; 16(7): 755-763. https://doi.org/10.1080/17461391.2015.1119197

31.Teplan J, Malý T, Zahálka F, Hráský P, Kaplan A, Hanus M, Gryc T.The level of aerobic capacity in elite youth soccer players and its comparison in two age categories. Journal of Physical Education and Sport, 2012; 12(1): 129-134. 


\section{Information about the authors:}

Serdar Bayrakdaroğlu; (Corresponding Author); https://orcid.org/0000-0002-2166-6675; bayrakdaroglu85@gmail.com; School of Physical Education and Sport, Gumushane University ; 29000 Gumushane, Turkey.

Erdal Arl; https://orcid.org/0000-0003-1348-7930; arierdal@hotmail.com; School of Physical Education and Sport, Ordu University ; 52000 Ordu, Turkey:

Hüseyin Özkamçı; https://orcid.org/0000-0003-3372-2299; huseyinozkamci@gmail.com; Faculty of Sport Sciences, Dokuz Eylul University; 35000 Izmir, Turkey.

İbrahim Can; https://orcid.org/0000-0002-2050-1473; ibrahimcan_61_@hotmail.com; School of Physical Education and Sport, Igdir University; 76000 Igdir, Turkey:

\section{Cite this article as:}

Bayrakdaroğlu S, Arı E, Özkamçı H, Can I. The examination of Yo-Yo intermittent recovery test performance of young soccer players at different playing positions. Physical Education of Students, 2020;24(4):235-241.

https://doi.org/10.15561/20755279.2020.0406

This is an Open Access article distributed under the terms of the Creative Commons Attribution License, which permits unrestricted use, distribution, and reproduction in any medium, provided the original work is properly cited http://creativecommons.org/licenses/by/4.0/deed.en

Received: 17.06.2020

Accepted: 02.08.2020; Published: 30.08 .2020 